UDC $546.26(620.3): 544.18$

\title{
PROPERTIES OF HEXAGON-SHAPED CARBON NANOCLUSTERS
}

\author{
O.S. Karpenko, V.V. Lobanov *, N.T. Kartel \\ Chuiko Institute of Surface Chemistry of National Academy of Sciences of Ukraine \\ 17 General Naumov Str., Kyiv, 03164, Ukraine
}

Equilibrium spatial structures of hexagon-shaped carbon nanoclusters (CNC) of $C_{6}-C_{216}$ size in the electronic ground-states were calculated by means of a density functional theory method (B3LYP, basis set 6-31 $\left.G^{* *}\right)$. Some relevant features were revealed:

- $C_{6}$ and $C_{24} C N C s$ are ground-state singlets, $C_{54}$ and $C_{150}$-ground-state triplets, and $C_{96}$ and $C_{216}-$ ground-state quintets;

- the $\pi$-system of outer cyclic chains is only weakly bound to the $\pi$-system of the central part of the nanocluster;

- the single-electron energy level spectrum shows that the energy levels of vacant MOs in the outer cyclic chain are located within the energy interval of the highest occupied MOs.

These features have been explained on the basis of the distribution of spin density of the doublecoordinated carbon atoms of the outer cyclic chain of the nanoclusters.

Together with improving techniques of obtaining reproducible samples of graphene [1], a plenty of the works has been devoted to investigation of their physical $[2,3]$ and chemical $[4,5]$ properties. The zone structure of graphene (a linear character of the dispersion law of charge carriers in the vicinity of Fermi level) [2] atypical for the most solids predetermined an increased interest to it as to a perspective material for molecular electronics. The same property determines also a linear character of the dependence of the single-electron state energies on the number of both Bloch functions in case of solid or molecular orbital (MO) when considering finite size systems, what affects on their chemical properties.

Graphene is a crystal formed by a twodimensional system of carbon atoms. Cutting down a graphene sheet both-side with $\mathrm{C}-\mathrm{C}$ bonds splitting or by selecting stripes in it due to chemical modification [6], it is possible to obtain unidimensional nanoribbons [7] with open edges which are suitable for creation of nanoelectronic devices. Due to further limitation of each side of unidimensional nanoribbons, clusters of certain shape are formed. Such clusters are identified with the zero-dimensional systems and, at suitable sizes, they can be called as carbon nanodots with properties strongly dependent on the form and type of atomic chains framing them [8]. Carbon nanoclusters (CNC), as a rule, are limited to two types of borders - zigzag and similar to the "elbow-rest of arm-chair". It is the type of these borders that influences on the electronic structure of CNC and determines their specific physical [9] and chemical [10] properties. As supposed in [11] these single-, double-, three-, and four-layer graphene fragments, probably form activated carbon fibers, which has a high specific surface area during gases adsorption [12] or in the lithium batteries with enhanced capacity [13]. The presence of broken bonds at the peripheral carbon atoms results in the fact that, despite the even amount of electrons in such systems, their electronic ground-state (EGS) should not necessarily be a singlet one, and, consequently, the theory predicts magnetization of CNC [14]. A localization of spin density at the zigzag edges of $\mathrm{CNC}$ was recently found from magneticallypower microscopic experiments [15]. The information concerning the multiplicity of $\mathrm{CNC}$ EGS, features of their spatial structure, details of distributions of electronic and spin densities, and also molecular electrostatic potential is important for prognostication of $\mathrm{CNC}$ reactivity and catalytic activity [16]. In perspective they can be used as memory units for quantum computers [17] and in various chemical applications [10]. 
Presented here are the results of theoretical investigations on the properties of $\mathrm{CNC}$ with ideal hexagonal form limited to six zigzag edges, i.e. with the uniform borders, and condensed polycyclic aromatic molecules (PAM) with a nalogical structure. All the calculations were performed by the density functional theory method $[18,19]$ with exchange-correlation potential B3LYP $[20,21]$ and basis set $6-31 \mathrm{G}^{* *}$, applying no symmetry conditions, using the US GAMESS program package [22]. Absence of the negative eigenvalues in Hessian was used as a confirmation of the total energy minimum for the obtained optimized structures of $\mathrm{CNC} \mathrm{C}_{6}-\mathrm{C}_{216}$ and PAM.

A regular hexagonal cluster with composition of $\mathrm{C}_{6}$ was the first considered $\mathrm{CNC}$ model. The second one was built from the first cluster edged with zigzag cyclic carbon chain (Fig. 1) which resulted in a cluster with gross-formula of $\mathrm{C}_{24}$. Applying similar procedure, $\mathrm{CNC}$ models were formed with composition of $\mathrm{C}_{54}, \mathrm{C}_{96}, \mathrm{C}_{150}$, and $\mathrm{C}_{216}$, their general structural characteristics are shown in the Table 1. PAMs were built from corresponded $\mathrm{CNC}$ by attaching hydrogen atoms to the peripheral doubly coordinated carbon atoms $\left(\mathrm{C}^{(2)}\right)$.

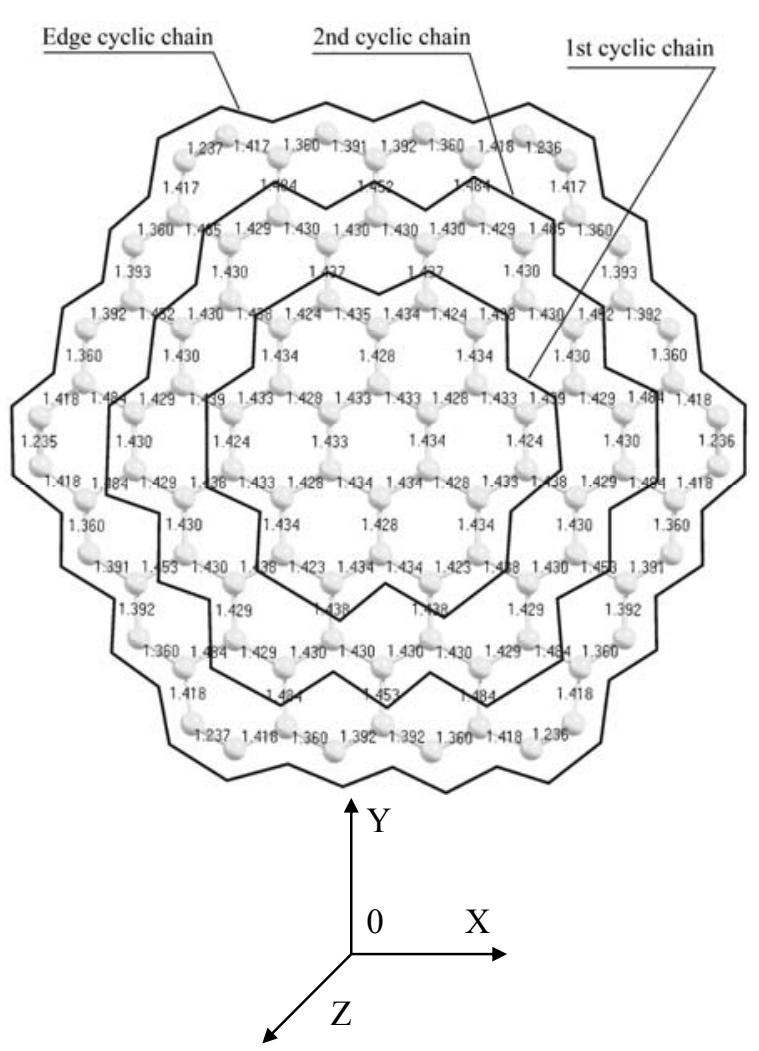

Fig. 1. $\mathrm{C}-\mathrm{C}$ bond lengths of the equilibrium structure of the $\mathrm{C}_{96}(\mathrm{M}=5)$ carbon nanocluster in the electronic ground state

Table 1. General structural characteristics of the considered CNC

\begin{tabular}{cccccc}
\hline No & $\begin{array}{c}\text { Number } \\
\text { of atoms }\end{array}$ & $\begin{array}{c}\text { Number of } \\
\text { hexagons }\end{array}$ & $\begin{array}{c}\text { Number of C-C } \\
\text { bonds }\end{array}$ & $\begin{array}{c}\text { Number of atoms } \\
\text { within single edge }\end{array}$ & $\begin{array}{c}\text { Number of double- } \\
\text { coordinated atoms } \\
\text { within single edge }\end{array}$ \\
\hline 1 & 6 & 1 & 6 & 1 & 1 \\
2 & 24 & 7 & 30 & 3 & 2 \\
3 & 54 & 19 & 72 & 5 & 3 \\
4 & 96 & 37 & 132 & 7 & 5 \\
5 & 150 & 61 & 210 & 9 & 6 \\
6 & 216 & 91 & 306 & 11 & 5 \\
\hline
\end{tabular}

Optimization of the spatial structure of $\mathrm{CNC}$ $\mathrm{C}_{6}-\mathrm{C}_{216}$ with definite multiplicity (M) has shown that the EGS for $\mathrm{C}_{6}$ and $\mathrm{C}_{24}$ clusters was singlet, for the rest clusters - high-spin states triplet and quintet (Table 2).

Dependence of the atomization energy $\left(\mathrm{E}_{\mathrm{at}}{ }^{\#}\right)$ per carbon-carbon bond calculated for EGS of $\mathrm{C}_{6}-\mathrm{C}_{216} \mathrm{CNC}$ on the number of carbon atoms is illustrated in the Fig. 2. It shows, that for the first representatives $\left(\mathrm{C}_{6}-\mathrm{C}_{54}\right)$ of this row $\left(\mathrm{C}_{6}-\mathrm{C}_{216}\right)$ the $E_{a t}^{\#}$ value almost exponentially decreases with the increase in numbers of carbon atoms. Starting from $\mathrm{C}_{96}$, this value becomes linearly dependent on the cluster size. That is why the $\mathrm{E}_{\mathrm{at}}^{\#}$ parameter can be chosen as a dominant characteristic for controlling the cluster size sufficient enough for the adequate reproducing of the properties of all representatives of the row. The results of calculations on the properties of $\mathrm{CNC} \mathrm{C}_{96}-\mathrm{C}_{216}$ showed them to be analogous and testified their weakly dependence on the amount of carbon in the cluster. Therefore, further consideration will be illustrated for the data obtained for $\mathrm{CNC}_{96}$ in the EGS (M=5, see Table 2).

As follows from the Fig. 1, all the $\mathrm{C}-\mathrm{C}$ bond lengths of central hexagon of $\mathrm{CNC} \mathrm{C}_{96}(\mathrm{M}=5)$ are within 1.433-1.434 $\AA$ (those in benzene molecule are of $1.399 \AA$ ). The equality of bond lengths of central hexagon is also characteristic of all the 
representatives of the $\mathrm{CNC}$ row considered, for EGS these lengths are: $\mathrm{C}_{24}(\mathrm{M}=1)-1.451 ; \mathrm{C}_{54}$ $(\mathrm{M}=3)-1.432 ; \mathrm{C}_{150}(\mathrm{M}=3)-1.429 ; \mathrm{C}_{216}(\mathrm{M}=5)-$ $1.427 \AA$. A clear tendency of shortening bonds for the EGS of studied CNC with the increase in the number of atoms is observed. The central hexagon in $\mathrm{C}_{96} \mathrm{CNC}$ is edged by the first (I) cyclic chain of carbon atoms where an alternation of bond lengths from 1.424 to $1.434 \AA$ is already noticeable, they are within an interval between the $\mathrm{C}-\mathrm{C}$ bond lengths in ethane $(1.534 \AA)$ and ethene $(1.337 \AA)$. Lengths of six bonds between atoms of the central hexagon and the first cyclic chain are identical and equal to $1.428 \AA$. In the second (II) cyclic carbon chain, enclosing the first one, all the $\mathrm{C}-\mathrm{C}$ bond lengths are practically identical (1.429-1.430 $\AA$ ). The interatomic bond lengths between the first and the second cyclic chains are almost the same (1.437-1.439 $\AA$ ) and exceed analogous bond lengths between the central hexagon and the first cyclic chain. Every of six identical edges of the $\mathrm{CNC}$ consists of seven carbon atoms, two of them take part in the formation of the other almost triple carbon-carbon bonds with length of $1.236 \AA$ (that in acetylene is of $1.212 \AA$ ). Noticeable alternation of bond lengths is seen in each of six regional heptatomic fragments; the length of some short of them is $1.360 \AA$ what is somewhat greater than double bond length in ethene. It is very substantial that the atoms of edge chain are bound to atoms of the cyclic chain II by long enough bonds (1.452 to $1.484 \AA$ ) what noticeably exceeds the bond length in benzene (1.399 $\AA$ ). Therefore, it is possible to suppose that the $2 p_{z}$ atomic orbitals of edge carbon atoms poorly enough participate in the conjugation with those of the rest atoms of $\mathrm{CNC} \mathrm{C}_{96}$. Thus, the $\pi$-system of edge chain should be considered as a system relatively isolated from the central part of the cluster.

Table 2. Energy values (eV) of some selected nanoclusters of varying size $\left(\mathrm{C}_{6}-\mathrm{C}_{216}\right)$ and at different spin states

\begin{tabular}{ccccccc}
\hline \begin{tabular}{c} 
Elect- \\
ronic \\
state \\
\cline { 2 - 7 } $\begin{array}{c}\text { multi- } \\
\text { plicity }\end{array}$
\end{tabular} & $\mathbf{C}_{\mathbf{6}}$ & $\mathbf{C}_{\mathbf{2 4}}$ & $\mathbf{C}_{\mathbf{5 4}}$ & $\mathbf{C}_{\mathbf{9 6}}$ & $\mathbf{C}_{\mathbf{1 5 0}}$ & $\mathbf{C}_{\mathbf{2 1 6}}$ \\
\hline 1 & 0 & 0 & 5.60 & 7.66 & 12.18 & 13.56 \\
3 & 1.17 & 2.74 & 0 & 1.65 & 0 & 0.39 \\
5 & 2.14 & 2.96 & 0.70 & 0 & 1.57 & 0 \\
7 & ---- & 7.64 & 2.12 & 1.05 & 2.81 & 0.80 \\
\hline
\end{tabular}

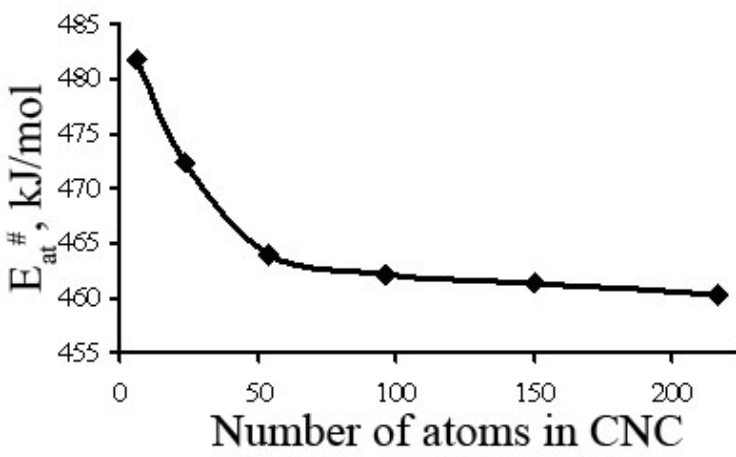

Fig. 2. Atomization energy averaged over all the $\mathrm{C}-\mathrm{C}$ bonds in a $\mathrm{C}_{6}-\mathrm{C}_{216}$ cluster as a function of the cluster size

The equilibrium structure of PAM $\mathrm{C}_{96} \mathrm{H}_{24}$ (see Fig. 3) in EGS $(\mathrm{M}=1)$ somewhat differs from that of $\mathrm{CNC} \mathrm{C}_{96}$ considered above. At the zigzag edge, the carbon-carbon bond length are only $1.362 \AA$, i.e. insignificantly differ from that in alkenes. In addition, the bond lengths between atoms of edge and second cyclic chains are within 1.436-1.441 $\AA$, considerably lower than those in $\mathrm{CNC}_{96}$. As a result, the $2 p_{z}$ orbitals of the atoms of edge chain form a united conjugated system with the similar atom orbitals of carbon atoms for the rest part of $\mathrm{C}_{96} \mathrm{H}_{24}$ molecule.

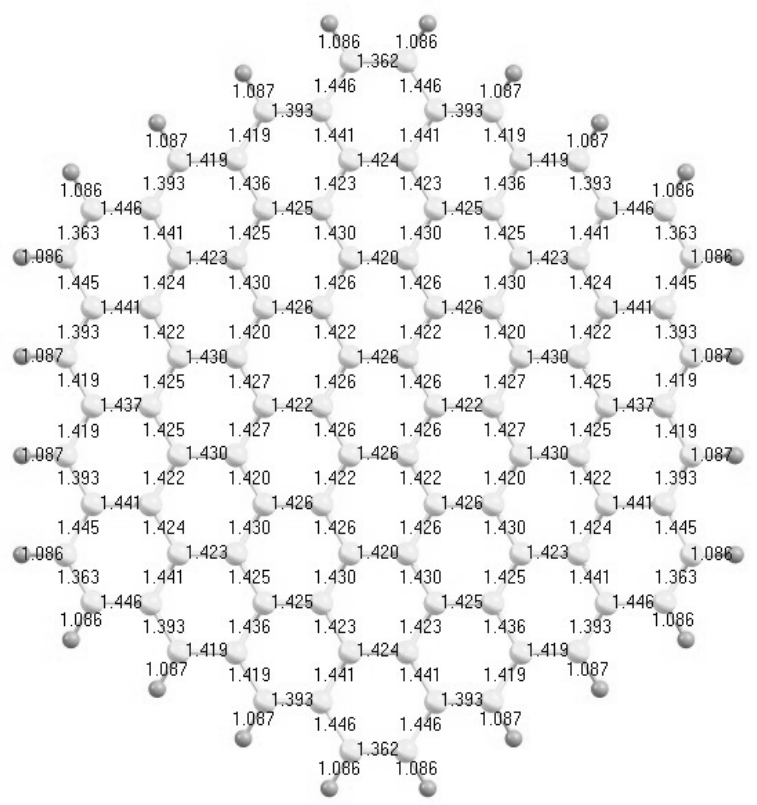

Fig. 3. $\mathrm{C}-\mathrm{C}$ and $\mathrm{C}-\mathrm{H}$ bond lengths of the groundstate equilibrium structure of $\mathrm{C}_{96} \mathrm{H}_{24}(\mathrm{M}=1)$

The presence of the localized triple $\left(\mathrm{CNC} \mathrm{C}_{96}\right)$ and double (PAM $\mathrm{C}_{96} \mathrm{H}_{24}$ ) carbon-carbon bonds testifies the possibility of their participation in the reactions of electrophilic addition. In case of PAM, the reactions of substitution are also eventual. 
When attacking an unsaturated bond, a reagent molecule is considerably polarized at the vicinity. The degree of such polarization can be found from the molecular electrostatic potential $(\rho)$ distributions showed in the Fig. 4. It is seen from the Fig. 4 that in plane of $\mathrm{CNC} \mathrm{C}_{96}$ (X0Y plane) near each of the triple bonds a compact area of negative values of potential is localized. It follows from the distribution of electrostatic potential within the ZOY plane (perpendicular to the X0Y plane and passing through the centers of a pair of peripheral triple bonds (Fig. $4 \mathrm{~b}$ )) that the area of negative $\rho$ values is spread to infinitely large distance from the centers of negative charge. It concedes a possibility of a barrier-free access of cations and small proton donor molecules to triple bonds.

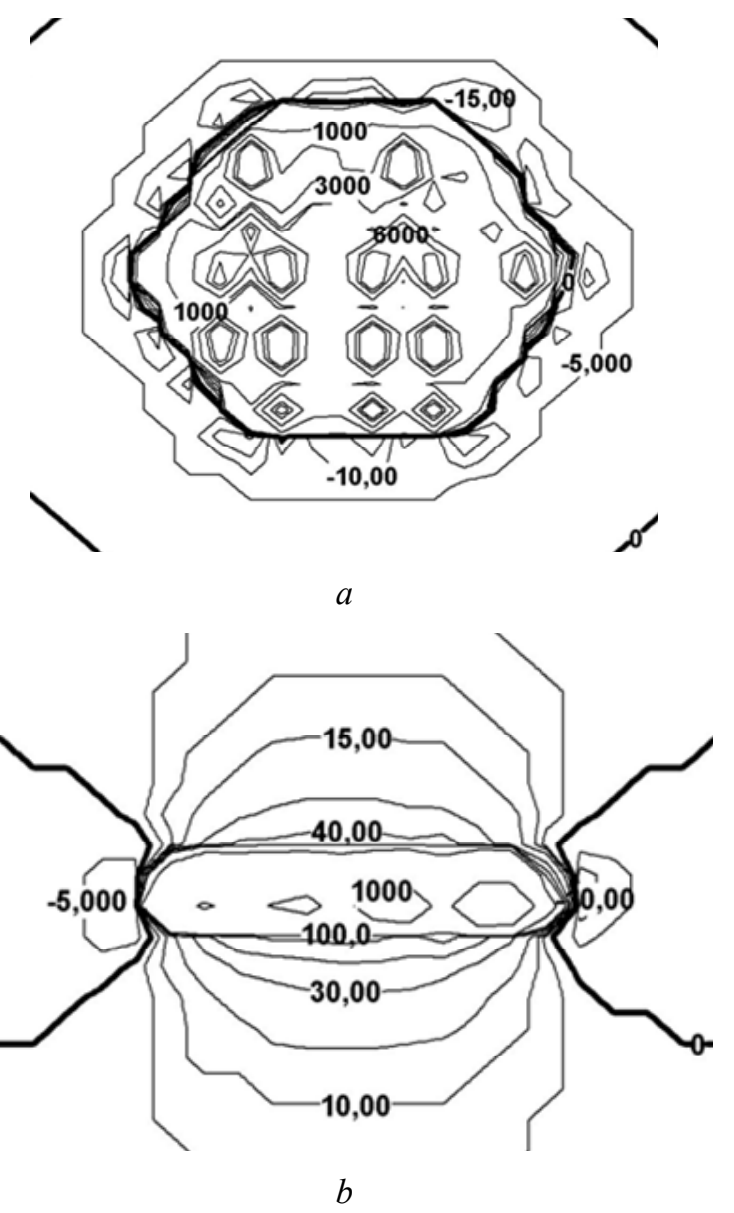

Fig. 4. Distribution of $\rho(\mathrm{kJ} / \mathrm{mol})$ in the plane of the $\mathrm{C}_{96} \mathrm{CNC}(a)$, and in a plane perpendicular to the $\mathrm{CNC}(b)$

Thus, despite the $\mathrm{CNC} \mathrm{C}_{96}$ consists of atoms of only one type (carbon atoms), the distribution of molecular electrostatic potential for EGS $(M=5)$ in its vicinity is far from homogeneity. Such anisotropy in $\rho$ distribution causes a specific behavior of CNC towards proton donor reagents as well as electron donor ones. Besides, the idea about distribution of molecular electrostatic potential allows getting an evident and unambiguous specification of the centers of primary interaction between $\mathrm{CNC}$ and polar molecules.

The quintet EGS of $\mathrm{CNC} \mathrm{C}_{96}$ testifies that the number of electrons with the up spin ( $\alpha$-subsystem) exceeds for 4 the number of electrons with the down spin ( $\beta$-subsystem), which is prerequisite for possibility of using these nanoclusters as nanomagnets. Reliable experimental proofs [23] appeared lately along with respective theoretical grounds [24] about the existence of magnetic sorting in the nanostructures consisting of atoms of $\mathrm{s}$ - and p-elements. The origin of their magnetism is explained within the framework of two approaches.

According to the first approach the nanosystem should have defects of crystalline lattice; those could be not fully coordinated carbon atoms at the edge of $\mathrm{CNC}$ which raise the local magnetic moments of different type of organization. The second approach is based on the assumption that for the clusters of some spatial forms a high degeneracy multiplicity of single-electron levels takes place in the vicinity of the Fermi level. According to the Hund's rule for the degenerate states of atoms and molecules, this results in possibility of their single filling and so to breaking up of the electronic system into two $\alpha$ - and $\beta$-subsystems, i.e. to appearance of a magnetic moment in the EGS of nanocluster.

A spectrum of single-electron energy levels $\left(\varepsilon_{i}\right)$ for EGS of $\mathrm{C}_{96} \mathrm{CNC}$ is shown in the Fig. 5. Its atypical view indicates that for the single-electron energy level spectrum, energy levels of vacant MOs in the outer cyclic chain are located within the energy interval of the highest occupied MOs. There are four such MOs $(\alpha 291-\alpha 294)$ for $\alpha$-subsystem and seven MOs ( $\beta 287-\beta 293)$ for $\beta$-subsystem. The filling of this scheme is caused by the necessity to satisfy two slightly contradictory requirements. The first of them is obvious - those MOs which provide the energy minimum of entire system are filled first of all. The second requirement is caused by the specificity of the considered object, namely by the presence of doubly coordinated edge carbon atoms with uncompensated bonds, a single-electron state being localized on each of them.

The analysis of MO structure of $\alpha$-subsystem showed that the lowest vacant MOs which are 
situated upper than occupied ones, are practically delocalized over entirely cluster (Fig. $6 a$ ) and have antibonding $\pi^{*}$-character with an insignificant binding in the central hexagon area. The same type of orbitals (vacant ones) located in the energy range of occupied MOs are delocalized over cluster periphery only and concentrated over the triple and almost double bonds of edge cyclic chain (see Figs. 2 and $6 b$ ). Therefore filling of these MOs excludes a possibility of localization of the electronic states over uncompensated bonds of the doubly coordinated border carbon atoms. Each of frontal occupied MOs (Fig. $6 c$ ) is almost fully localized on one of the edges of $\mathrm{C}_{96} \mathrm{CNC}$, has quite a complicated topology and can be realized in the states localized over uncompensated bonds. Analogical conclusions are also correct for the $\beta$-subsystem.

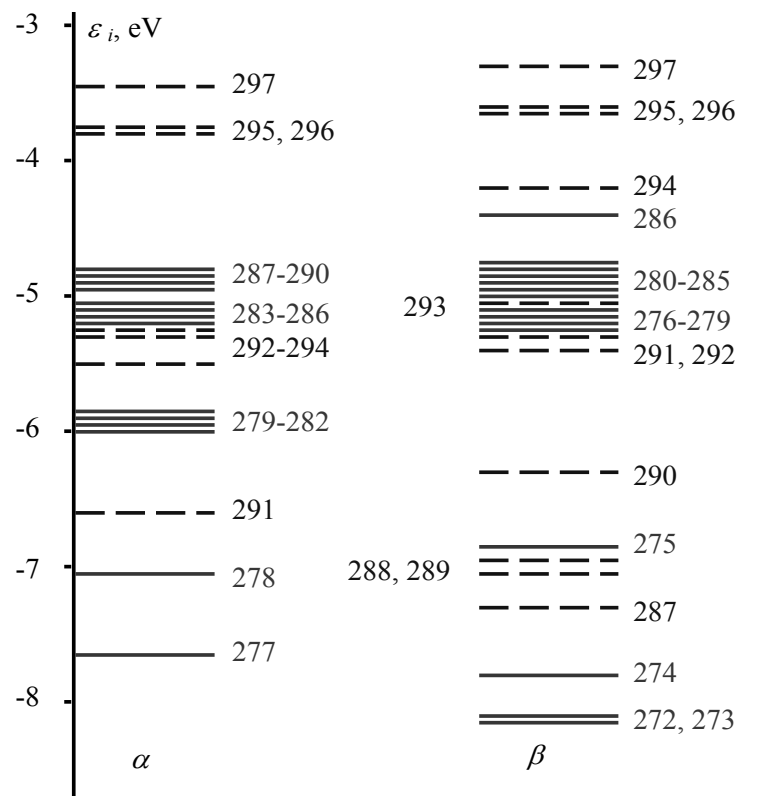

Fig. 5. Single-electron energy levels of the frontal MO of the $\alpha$ - and $\beta$-subsystems of the $\mathrm{C}_{96}$ nanocluster in the ground state (solid lines: occupied MOs, dotted lines: unoccupied MOs)

Considering the $\mathrm{CNC}$ as a molecule, it is impossible to talk about its Fermi level as well, but it can be identified as the energy of the highest occupied molecular orbital (HOMO). It is seen from the Fig. 5, that the mutual location of single-electron energy levels for EGS of $\mathrm{C}_{96}(\mathrm{M}=5)$ is such that the energy levels of some occupied MOs of $\alpha$ subsystem are in the energy range of the lowest unoccupied molecular orbitals of the $\beta$-subsystem and vice versa. It testifies that this system is entirely a half-metallic paramagnetic. According to this determination [25], such substances or materials are characterized by nonzero density of the states at the Fermi level for the one spin projection (in this case for $\alpha$-subsystem) but have a forbidden gap for the opposite projection of the spin ( $\beta$-subsystem). As a result, the conductivity of half-metallic magnetics occurs over spin subsystems individually, and such structures has spin-dependent transport properties. Various types of magnetic organization can be realized in half-metallic magnetics: ferro-, antiferro-, and ferrimagnetic ones. Graphene as infinite twodimensional hexagonal lattice of carbon atoms has properties of a diamagnetic semimetal.

To determine donor-acceptor properties of any system, two main properties are important: ionization potential (IP) and electron affinity (EA). It is seen in the Fig. 5 that during ionization of $\mathrm{C}_{96}$ $\mathrm{CNC}(\mathrm{M}=5)$ an electron leaves the $\mathrm{MO} \beta 286$ and the multiplicity of $\left[\mathrm{C}_{96}\right]^{+} \mathrm{CNC}$ ion becomes equal to four. When adding electron, a $\left[\mathrm{C}_{96}\right]^{-}$ion appears with filled MO $\beta 294$ (see Fig. 5). The calculated vertical IP as a difference between the total energy of $\left[\mathrm{C}_{96}\right]^{+}$ion $(\mathrm{M}=4)$ for the equilibrium configuration of $\mathrm{C}_{96} \mathrm{CNC}(\mathrm{M}=5)$ and the total energy of the neutral state of $\mathrm{C}_{96}$ cluster for equilibrium configuration was $6.28 \mathrm{eV}$. When calculating the adiabatic IP, the energies of equilibrium configurations of ion $\left[\mathrm{C}_{96}\right]^{+}(\mathrm{M}=4)$ and that of $\mathrm{C}_{96} \mathrm{CNC}(\mathrm{M}=5)$ were used. The value obtained was $6.25 \mathrm{eV}$. Slight difference between vertical and adiabatic IPs testifies to insignificant alteration of the $\mathrm{C}_{96} \mathrm{CNC}$ structure under ionization. Calculations for $\mathrm{C}_{96} \mathrm{H}_{24}$ PAM gave the values of 5.46 and $5.44 \mathrm{eV}$ for vertical and adiabatic IPs respectively, what reflects less electron donor capability of $\mathrm{C}_{96} \mathrm{CNC}$ in EGS as compared to that of analogical polyaromatic molecule. At the same time, it should be noted that the experimental value of IP for benzene is $9.2 \mathrm{eV}$, for naphthalene $-8.12 \mathrm{eV}$ [26], what testifies a substantial growth of electron donor properties of $\mathrm{C}_{96} \mathrm{H}_{24} \mathrm{PAM}$ as compared to that of the simplest aromatic molecules. The calculated values of vertical and adiabatic EA of EGS for $\mathrm{C}_{96}$ $\mathrm{CNC}(\mathrm{M}=5)$ are 2.34 and $2.58 \mathrm{eV}$ respectively. It allows to suppose that electron acceptor capability of the studied system is higher than that of $\mathrm{C}_{96} \mathrm{H}_{24} \mathrm{PAM}$ (the calculated values of EA are of 1.74 (vertical) and $1.77 \mathrm{eV}$ (adiabatic)). For benzene and naphthalene the experimental data on electron affinity are very contradictory and ambiguous within the interval from -1.63 to $0.68 \mathrm{eV}$ [26]. If for the simplest PAMs (benzene and naphthalene) their 
electron acceptor properties are uncertain, there is no doubt in case of $\mathrm{C}_{96} \mathrm{CNC}$ and PAM $\mathrm{C}_{96} \mathrm{H}_{24}$.
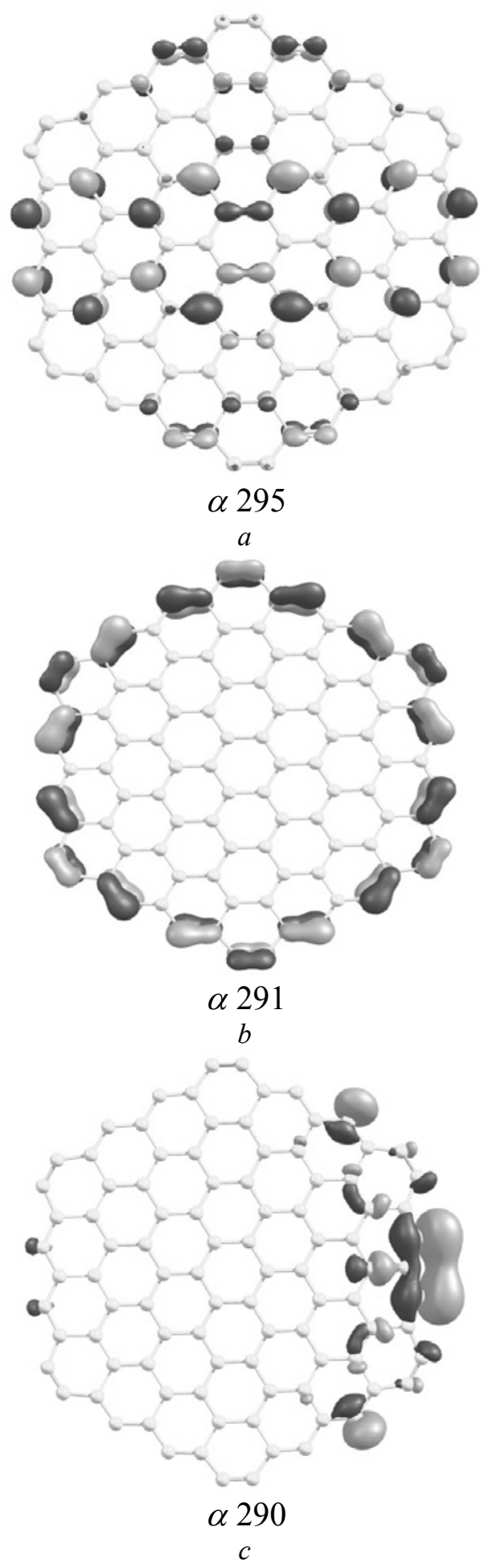

Fig. 6. Spatial localization of the MOs in the $C_{96}$ nanocluster. The lowest unoccupied MOs $(\alpha 295)$ are located upper than occupied MOs (a). Vacant MOs $(\alpha 291)$ are within the energy interval of occupied MOs $(b)$. Highest occupied MOs ( $\alpha 290)(c)$
It is seen from the Table 2 that the EGS of $\mathrm{C}_{24}$ $\mathrm{CNC}$ is singlet, what can be explained by the presence of only two carbon atoms within each of six borders, at the boundary junctions the pairs of these atoms (one from each of borders) form six triple bonds what results in absence of doubly coordinated atoms in the system and stipulates a zero value of spin of entire cluster. The EGS of next $\mathrm{C}_{54} \mathrm{CNC}$ is triplet, what can be explained taking into account the amount of atoms $\mathrm{C}^{(2)}$ within each of borders, that is equal to three (see the Fig. 7 a). Two of them take part in the formation of two triple bonds, and a spin density is localized on the third. Therefore, in entire cluster two magnetic sublattices are formed and the multiplicity of EGS appears to be equal to three. In the $\mathrm{C}_{96} \mathrm{CNC}$ each of borders contains four atoms $\mathrm{C}^{(2)}$. At two of them (with no triple bonding) spin density has the same sign, what generates a ferromagnetic organization of corresponding magnetic moments within each of borders. Four edges belong to the same type of magnetic sublattices ( $\alpha$-subsystem), and two edges belong to another sublattice type ( $\beta$-subsystem). So, the energy minimum (EGS) relates to the state with $\mathrm{M}=5$ with ferri-ordering of magnetic sublattices of the edges of entire cluster (Fig. $7 b$ ). Each of borders of the $\mathrm{CNC} \mathrm{C}_{150}$ contains three free atoms $\mathrm{C}^{(2)}$. Spin densities of identical sign are localized at these atoms of two opposite edges. Edges with ferri-ordering of magnetic moments are joined to these edges from both sides (see Fig. 7 c). As a result of such an organization, entire cluster $\mathrm{C}_{150}$ contains two uncoupled electrons and the multiplicity of EGS appears to be equal to three. By analogy, it is possible to explain also the quintet $\mathrm{EGS}$ of $\mathrm{C}_{216} \mathrm{CNC}$, where each of borders has even (four) amount of doubly coordinated carbon atoms (see the Fig. $7 d$ ).

Starting from the distribution of spin density in $\mathrm{CNC}$, it is possible to explain the reason of slight structure reconstruction of the $\mathrm{C}_{96} \mathrm{CNC}$ during transition to the negatively or positively singly charged clusters $\left[\mathrm{C}_{96}\right]^{-}$and $\left[\mathrm{C}_{96}\right]^{+}$. It is seen in the Fig. 8 that adding of one electron to the $\mathrm{C}_{96} \mathrm{CNC}$ results in a zero spin density at one of the doubly coordinated carbon atoms rather than in its delocalization over all the atoms of the cluster. When ionizing the $\mathrm{C}_{96} \mathrm{CNC}$, there is a change in the organization of spins within one of six borders. Similarly to the case of electron addition, its removal from the $\mathrm{C}_{96} \mathrm{CNC}$ causes the local change of the sign of spin density within single doubly coordinated carbon atom. 

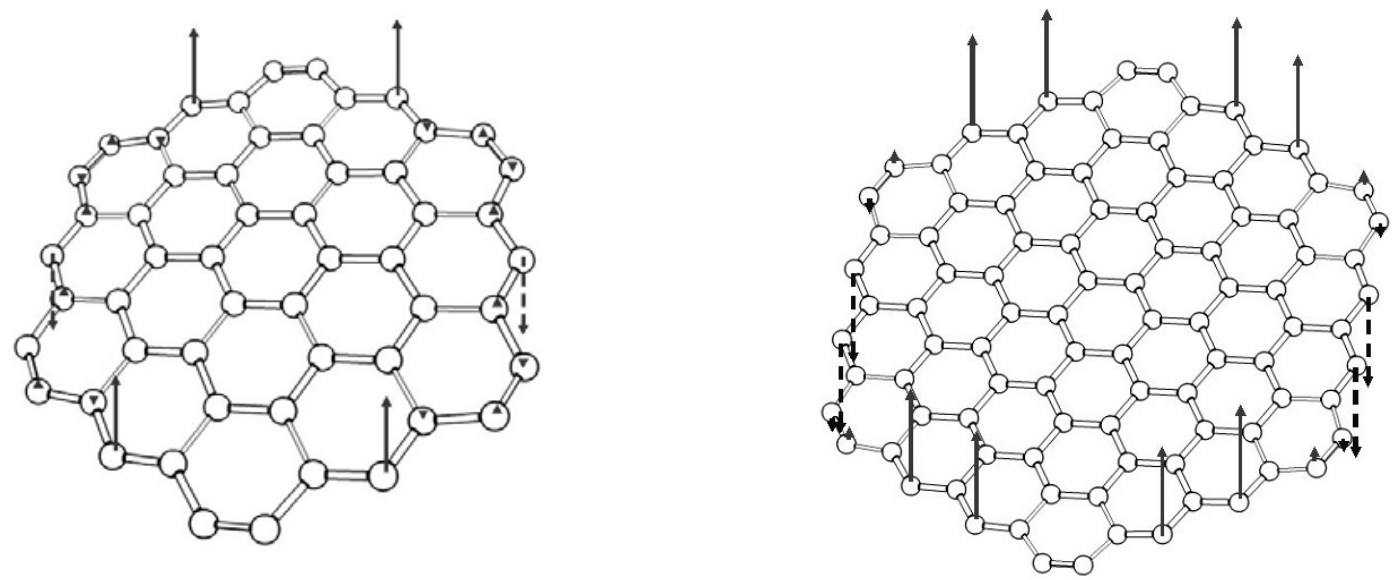

$a$

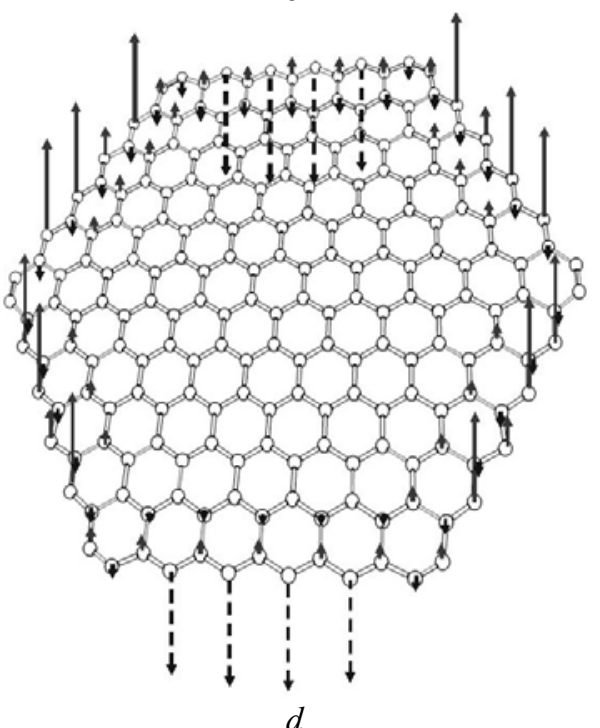

Fig. 7. Spin density distribution of some carbon nanoclusters of varying size: $\mathrm{C}_{54}(a), \mathrm{C}_{96}(b), \mathrm{C}_{150}(c)$ and $\mathrm{C}_{216}(d)$

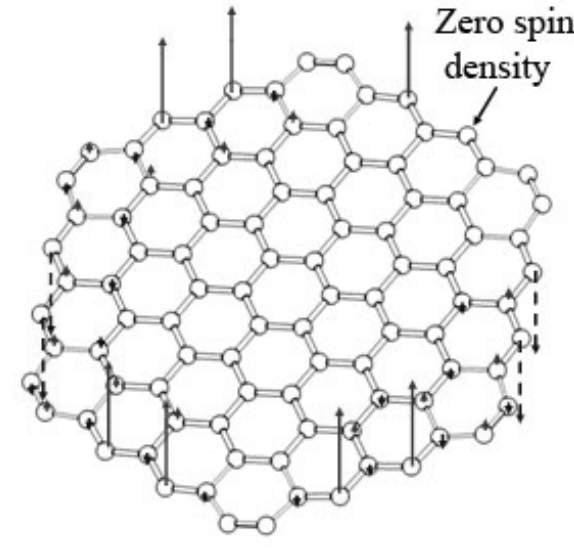

$a$

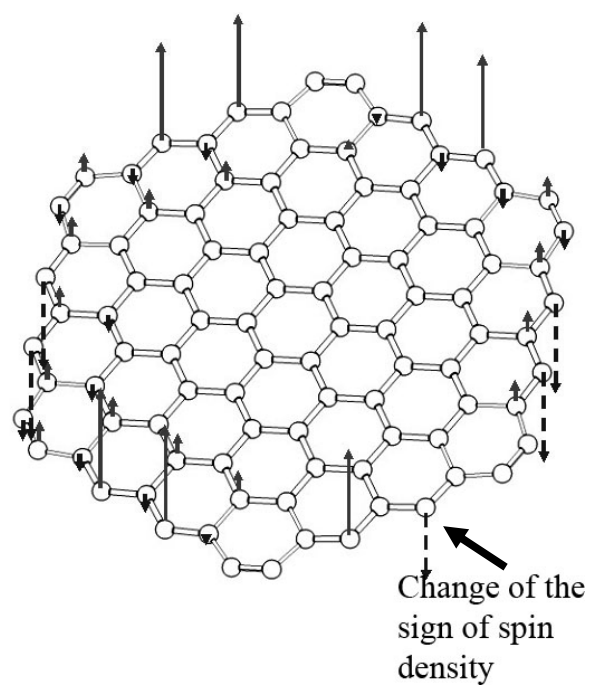

$b$

Fig. 8. Distribution of spin density in the $\left[\mathrm{C}_{96}\right]^{-}(a)$ and $\left[\mathrm{C}_{96}\right]^{+}(b)$ nanoclusters 
Thus, the results obtained allow us to conclude that the EGS of $\mathrm{C}_{54}-\mathrm{C}_{216} \mathrm{CNCs}$ of ideal hexagonal form is not singlet, despite they have even amount of electrons. Their spatial structures are such that the $2 p$-orbitals of edge cyclic chain form a conjugated system weakly bound with $\pi$-system of the central part of the cluster what allows to consider it as relatively independent system. Although the studied clusters are consisting of the same type of atoms (carbon), the distributions of molecular electrostatic potential for their EGS have significant anisotropies which determine their electron donor and proton donor properties. It is a characteristic of the spectrum of single-electron energy levels that the MOs up-diffused over the bonds of edge cyclic chain remain vacant although respective energy levels appear below than the energy values of some occupied MOs. The magnetic moments of the clusters having only zigzag edges are determined by the presence of doubly coordinated carbon atoms with edge electronic states strongly localized over them.

All these features should be taken into account when using considered $\mathrm{CNC}$ as an element base of molecular electronics.

\section{REFERENCES}

1. Novoselov K.S., Geim A.K., Morozov S.V. et al. Electric field effect in atomically thin carbon films // Science. - 2004. - V. 306, N 5696. - P. 666-669.

2. Novoselov K.S., Geim A.K., Morozov S.V. et al. Two-dimension gas of massless Dirac fermions in graphene // Nature. - 2005. V. 438. - P. 197-199.

3. Novoselov K.S., Jiang Z., Zhang Y. et al. Roomtemperature quantum hall effect in graphene // Science. - 2007. - V. 315. - P. 1379-1382.

4. Giannozzi P., Car R., Scoles G. Oxygen adsorption on graphite and nanotubes // J. Chem. Phys. - 2003. - V. 118, N 3. P. 1003-1006.

5. Wehling T.O., Novoselov K.S., Morozov S.V. et al. Molecular doping of graphene // Nano Lett. - 2008. - V. 8, N 1. - P. 173-177.

6. Chernozatonskiil L.A., Sorokin P.B., Brüning J.W. Two-dimensional semiconducting nanostructures based on single graphene sheets with lines of adsorbed hydrogen atoms // Appl. Phys. Lett. - 2007. - V. 91. - P. 183103-183105.

7. Stampfer C., Güttinger J., Hellmüller S. et al. Energy gapsin etched graphene nanoribbons
// Phys. Rev. Lett. - 2009. -V. 102. P. 056403-056406.

8. Nakada K., Fujita V.G., Dresselhause M.S. Edge state in graphene ribbon: nanometer size effect and edge shape dependence // Phys. Rev. B. - 1996. - V. 54. - P. 17954-17961.

9. Son Y.-W., Cohen M.L., Louie S.G. Half metallic graphene nanoribbons // Nature. 2006. - V. 444. - P. 347-351.

10. Jiang D., Sumpter B.G., Dai S. The unique chemical reactivity of a graphene nanoribbon's zigzag edge // J. Chem. Phys. 2007. - V. 126. - P. 134701-134711.

11. Kaneko K., Ishii C., Ruike M., Kuwabara H. Origin of superhigh surface area and microcrystalline graphitic structures of activated carbons // Carbon. - 1992. - V. 30. - P. 1075-1088.

12. Rao A.M., Fung A.W.P., Dresselhaus M.S. Endo $M$. Structural characterization of heattreated activated carbon fibers // J. Mater. Res. - 1992. - V. 7, N 7. - P. 1788-1794.

13. Sato K., Noguchi M., Demachi A. et al. A mechanism of lithium storage in disordered carbons // Science. - 1994. V. 264. - P. 556-558.

14. Yazyev O.V., Katsnelson M.I. Magnetic correlations at graphene edges: basis for novel spintronics devices // Phys. Rev. Lett. - 2008. - V. 100. - P. 047209-047212.

15. Črvenka J., Katsnelson M.I., Flipse C.F.J. Room-temperature ferromagnetism in graphite driven by two-dimensional networks of point defects // Nature Phys. 2009. - V. 5. - P. 840-844.

16. Boukhvalov D.W., Katsnelson M.I. Chemical functionalization of graphene with defects // J. Phys.: Condens. Matter. - 2009. - V. 21. P. 344205-344217.

17. Kotakoski J., Krasheninnikov A.V., Nordlund K. Energetics, structure, and long-range interaction of vacancy-type defects in carbon nanotubes: Atomistic simulations // Phys. Rev. B. - 2006. V. 74. - P. 245420-245425.

18. Kohn W., Sham L.S. Self-consistent equation including exchange and correlation effect // Phys. Rev. A. - 1965. - V. 140, N 4. - P. 1133-1138.

19. Parr R.G., Yang W. Density-functional theory of atoms and molecules - Oxford: Oxford Univ. Press, 1989. - $333 \mathrm{p}$.

20. Becke A.D. Density-functional thermochemistry. III. The role of exchange // J. Chem. Phys. - 1993. - V. 98. - P. 5648-5652. 
21. Lee C., Yang W., Parr R.G. Development of the Colle-Salvetti correlation-energy formula into a functional of the electron density // Phys. Rev. B. - 1988. - V. 37, N 2. - P. 785-789.

22. Schmidt M.W., Baldridge K.K., Boatz J.A. et al. General atomic and molecular electronic structure system // J. Comput. Chem. - 1993. V. 14. - P. 1347-1363.

23. Ohldag H., Tyliszszak T., Höhne R., Spemann D. $\pi$-Electron ferromagnetism in metal-free carbon probed bysoft X-ray dichroism // Phys. Rev. Lett. - 2007. - V. 98. - P. 187204-187209.
24. Son Y.-W., Cohen V.L., Louie S.G. Energy gaps in graphene nanoribbons // Phys. Rev. Lett. 2006. - V. 97. - P. 216803-216814.

25. De Groot R.A., Mueller F.M., van Engen P.G., Burchow R.H.J. New class of materials: halfmetallic ferromagnets // Phys. Rev. Lett. 1983. - V. 50, N 25. - P. 2024-2027.

26. Gurvich P.V., Karachentsev T.V., Kondratiev V.N. et al. Chemical Bond Breakage Energies, Ionising Potentials, and Electron Affinity. - Moscow: Nauka, 1974. - 351 p. (in Russian).

Received 30.10.2012, accepted 25.02.2013

\title{
Властивості вуглецевих нанокластерів гексагональної форми
}

\author{
О.С. Карпенко, В.В. Лобанов, М.Т. Картель
}

Інститут хімії поверхні ім. О.О. Чуйка Національної академії наук Украӥни вул. Генерала Наумова, 17, Київ, 03164, Україна, lobanov@isc.gov.иа

Методом теорії функиіоналу густини (В3LYP, базис 6-31 $G^{* *}$ ) розрахована рівноважна просторова будова основного електронного стану вуглецевих нанокластерів (ВНК) $C_{6}-C_{216}$ гексагональної форми. Встановлено, що:

- основний електронний стан ВНК $C_{6}, C_{24}$ синглетний, $C_{54} i C_{150}$ триплетний, $C_{96}$ та $C_{216}$ квінтетний;

- $\pi$-система крайового ичиклічного ланцюжка атомів вуглецю слабко зв'язана з $\pi$-системою центральної частини ВНК;

- енергії вакантних МО, розподілених по зв'язкам крайового ииклічного ланцююжка, потрапляють в діапазон енергій вищих зайнятих МО.

Встановленні особливості пояснено, виходячи з розподілу спінової густини по двократно координованим атомам вуглеиюю крайового ичиклічного ланцฺюжка.

\section{Свойства углеродных нанокластеров гексагональной формы}

\section{О.С. Карпенко, В.В. Лобанов, Н.Т. Картель}

Институт химии поверхности им. А.А. Чуйко Национальной академии наук Украины ул. Генерала Наумова, 17, Киев, 03164, Украина, lobanov@isc.gov.иа

Методом теории функиионала плотности (В3LYP, базис 6-31 G**) рассчитано равновесное пространственное строение основного электронного состояния углеродных нанокластеров (УНК) $C_{6}-C_{216}$ гексагональной формы. Установлено, что:

- основное электронное состояние УНК $C_{6}$ и $C_{24}$ синглетное, $C_{54}$ и $C_{150}$ триплетное, а $C_{96}$ и $C_{216}$ квинтетное;

- $\pi$-система краевой циклической цепи атомов углерода слабо связана с л-системой центральной части УНК;

- энергии вакантных МО, распределенных по связям краевой циклической цеепи, попадают в интервал энергий высших занятых МО.

Установленные особенности обьяснены, исходя из распределения спиновой плотности по двукратно координированным атомам углерода краевой цииклической цеепи. 